Invited paper to be presented at 6th International Symposium on Plasticity of Metals and Alloys, September 5-9, 1994, Prague, Czech Republic

\title{
PLASTIC DEFORMATION OF ORDERED INTERMETALLIC ALLOYS: FUNDAMENTAL ASPECTS
}

\author{
M. H. Yoo* \\ Max-Planck-Institut für Eisenforschung \\ Max-Planck-Str. 1, Postfach 140444 \\ D-40074 Düsseldorf, Germany
}

RECEIVED

SEP 231974

OSTI

Keywords: Intermetallic Alloys, NizAl, Ni3Si, NiAl, FeAl, TiAl, Ti3Al, Yield Stress, Flow Stress, Yield Strength Anomaly, Superdislocations, APB Energy, Elastic Anisotropy, Cross Slip, Climb Dissociation, APB Dragging, and Deformation Twinning

\section{ABSTRACT}

Fundamental aspects of plastic deformation in ordered intermetallic alloys are reviewed by directly comparing the temperature-dependent yield stresses of $\mathrm{Ni} 3 \mathrm{Al}$ and $\mathrm{Ni} 3 \mathrm{Si}$ (the $\mathrm{Ll}_{2}$ structure), $\mathrm{NiAl}$ and $\mathrm{FeAl}$ (the $\mathrm{B} 2$ structure), and TiAl and Ti3Al (non-cubic L10 and D019 structures, respectively). While the yield strength anomaly observed in $\mathrm{Ni} 3 \mathrm{Al}$ is consistent with the prevailing dislocation models, that found in stoichiometric $\mathrm{Ni} 3 \mathrm{Si}$ is not. The strong plastic anisotropy observed in NiAl stems from the high antiphase boundary energy, and that found in two-phase $\gamma-\mathrm{TiAl} / \alpha_{2}$ $\mathrm{Ti}_{3} \mathrm{Al}$ is due to the exceptionally high compressive yield strength along the caxis of TizAl.

\section{DISCLAIMER}

\begin{abstract}
This report was prepared as an account of work sponsored by an agency of the United States Government. Neither the United States Government nor any agency thereof, nor any of their employees, makes any warranty, express or implied, or assumes any legal liability or responsibility for the accuracy, completeness, or usefulness of any information, apparatus, product, or process disclosed, or represents that its use would not infringe privately owned rights. Reference herein to any specific commercial product, process, or service by trade name, trademark, manufacturer, or otherwise does not necessarily constitute or imply its endorsement, recommendation, or favoring by the United States Government or any agency thereof. The views and opinions of authors expressed herein do not necessarily state or reflect those of the United States Government or any agency thereof.
\end{abstract}

*Permanent Address: Oak Ridge National Laboratory, Oak Ridge, TN 37831, USA. 


\section{DISCLAIMER}

Portions of this document may be illegible in electronic image products. Images are produced from the best available original document. 


\section{INTRODUCTION}

Ordered intermetallic compounds based on transition-metal aluminides and silicides have been established as an important class of high-temperature materials because of their excellent elevated-temperature- strength, resistance to oxidation and corrosion, relatively low density, and high melting points. These properties have been well documented in several recent symposium proceedings [1-3].

Fundamental aspects of deformation behavior in this class of materials were assessed in an excellent review by Yamaguchi and Umakoshi [4], and future research areas of major importance were identified in a recent workshop report [5]. The strength of ordered intermetallics stems from the strong bonding between the dissimilar constituent atoms, which results in good stability of superlattice crystal structures, reduced diffusivity at high temperatures and low dislocation mobility, and, thus, increased resistance to plastic deformation at elevated temperatures.

The purpose of this paper is to make comparative assessments of the fundamental aspects of plastic deformation in $\mathrm{Ni} 3 \mathrm{Al}$ and $\mathrm{Ni} 3 \mathrm{Si}$ of the $\mathrm{L}_{12}$ structure, NiAl and FeAl of the B2 structure, and TiAl and Ti3Al of the noncubic Llo and D019 structures, respectively. Special emphasis will be placed on the anomalous (positive) temperature dependence of yield and flow stresses with increasing test temperature, the so-called yield strength anomaly. For each of the above three cases, the most representative experimental data will be summarized first, and then mechanistic understanding of physical source(s) for the yield strength anomaly will be reviewed on the basis of the available bulk and defect properties.

\section{YIELD STRENGTH ANOMALY}

Since the last compilation was made of the slip systems of those intermetallic alloys that exhibit the yield strength anomaly [6], some additional cases have been identified including $\mathrm{FeAl}$ [7] and $\mathrm{Ti3} \mathrm{Al}$ [8]. The solid curve in Fig. 1 shows schematically three possible regions of the temperature dependence of the critical resolved shear stress (CRSS), $\tau_{y}$, for the primary slip system at a typical strain rate, e.g., $\dot{\varepsilon}=10^{-4} \mathrm{~s}^{-1}$. The three temperature regions are defined as: (1) the descending low-temperature region $\left(0<\mathrm{T}<\mathrm{T}_{\mathrm{b}}\right)$ to the bottom $\left(\tau_{\mathrm{y}}=\tau_{\mathrm{b}}\right)$, (2) the intermediate temperature region $\left(T_{b}<T<T_{p}\right)$ between $\tau_{b}$ and the peak stress $\left(\tau_{p}\right)$, and $(3)$ the descending high-temperature region $\left(T_{p}<T<T_{c}\right)$, where $T_{c}$ is the orderdisorder transition temperature.

The glide resistance against the motion of superdislocations, which can contain the physical source of positive temperature dependence, may be expressed by a superposition of the two types of line glide resistance [9], the element glide resistance $\left(\tau_{\mathrm{e}}\right)$, and the resistance due to self-locking or other obstacles $\left(\tau_{r}\right)$, such that $\tau_{y}$ II $=\left\langle\tau_{e}\right\rangle+\left\langle\tau_{f}\right\rangle$, where the bracket denotes the average over the primary slip system. The former consists of the lattice resistance to the individual superpartials (Peierls stress, $\tau_{0}$ ) and that due to the fault dragging mechanisms [6], such as the antiphase boundary (APB) dragging proposed originally for the $\{110\}<111>$ slip in $\beta-C u Z n[10]$. The latter is related to the stress required to break away dynamically from any form of local barriers created by segments (out of the slip plane) such as the cross-slip pinning centers proposed for the $\{111\}<101>$ screw dislocations in the L12 alloys [11] and/or the climb-dissociated configurations [12] such as those observed in $\beta-\mathrm{CuZn} \mathrm{[13].}$ 


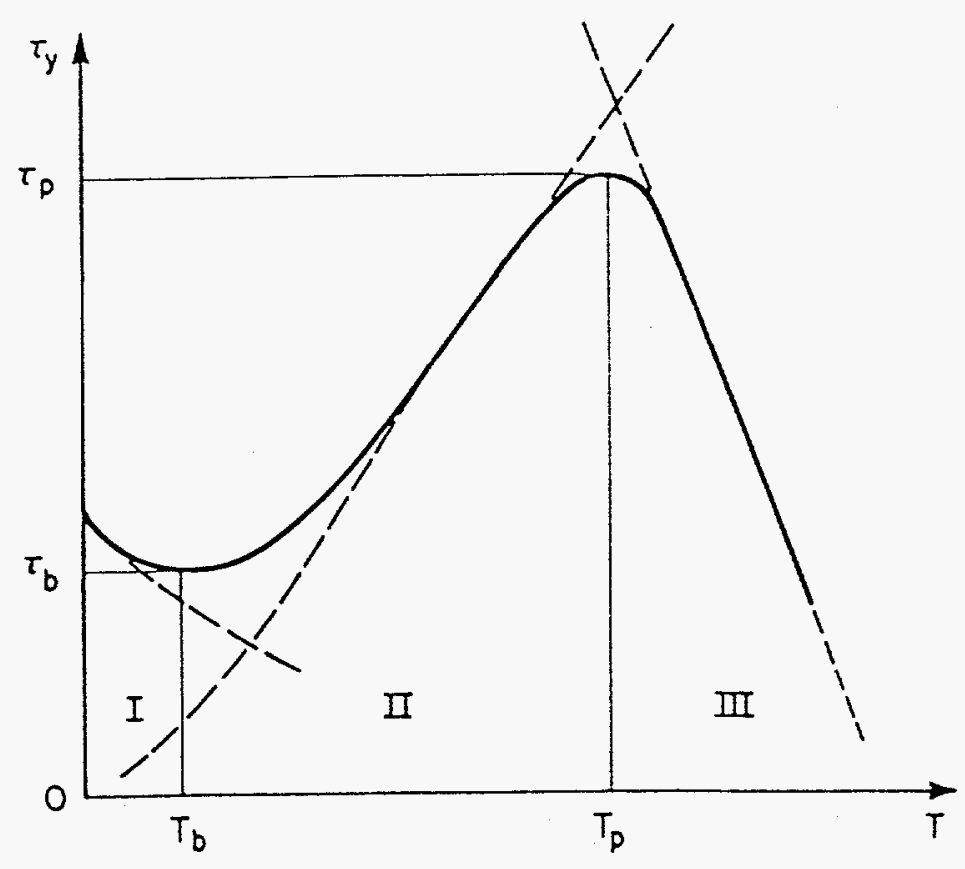

Figure 1. Temperature dependence of yield strength in ordered intermetallic alloys.

In order to make comparative analyses more conducive to mechanistic understanding, the plots of $\tau_{y}$ (or compressive yield stress, $\sigma_{y}$, defined by the $0.2 \%$-offset method) versus $\mathrm{T}$ are normalized to the elastic shear modulus, $\mathrm{G}$, and $\mathrm{T}_{\mathrm{c}}$, respectively. Table 1 lists pertinent bulk properties for those alloys to be discussed, where the values of $T_{c}$ were obtained from a handbook [14], and the mass densities and the elastic bulk and shear moduli were determined from the calculated lattice parameters and elastic constants at the ground state $(0 \mathrm{~K})$ [15-19].

For the aluminides listed in Table 1 (i.e., with the exception of Ni3Si), temperature-dependent yield stress data on single crystals have been reported in the literature. We will limit our discussion in this paper to the case of compressive loading along or near the [001] axis. This will enable us to focus on some key issues, such as the intrinsic driving force for cross slip in the $\mathrm{L}_{2} 2$ structure, the extensive plateau region in B2 aluminides, and the strong plastic anisotropy in two-phase Ti-rich $\gamma$-TiAl alloys.

Table 1. Bulk Properties of Ordered Intermetallic Alloys

\begin{tabular}{lllrrr}
\hline & & \multicolumn{3}{c}{$(\mathrm{GPa})$} & \\
\cline { 4 - 6 } & $\mathrm{T}_{\mathrm{c}}(\mathrm{K})$ & $\rho\left(\mathrm{g} / \mathrm{cm}^{3}\right)$ & $\mathrm{B}$ & $\mathrm{G}$ & \\
& & & & & \\
\hline & & & & & \\
$\mathrm{Ni}_{3} \mathrm{Al}$ & 1658 & 7.9 & 172 & 86 & {$[13]$} \\
$\mathrm{Ni}_{3} \mathrm{Si}$ & 1308 & 7.9 & 257 & 126 & {$[14]$} \\
$\mathrm{NiAl}$ & 1911 & 6.4 & 186 & 68 & {$[15]$} \\
$\mathrm{FeAl}$ & 1488 & 6.1 & 183 & 123 & {$[15]$} \\
$\mathrm{TiAl}$ & 1753 & 4.0 & 125 & 70 & {$[16]$} \\
$\mathrm{Ti}{ }_{3} \mathrm{Al}$ & 1453 & 4.5 & 129 & 72 & {$[17]$} \\
\hline
\end{tabular}




\section{Ni-BASE L12 ALLOYS}

Figure $2(a)$ shows schematically the yield strength anomaly observed in polycrystalline $\mathrm{Ni3} \mathrm{Al}$ [20] and $\mathrm{Ni}$-rich $\mathrm{Ni} 3 \mathrm{Si}$ [21]. The average grain sizes were estimated to be 400 to $500 \mu \mathrm{m}$ in $\mathrm{Ni} 3 \mathrm{Al}$ and about $20 \mu \mathrm{m}$ in Ni3Si [22]. Smaller grain size obtained in $\mathrm{Ni} 3 \mathrm{Si}$ was attributed to the grain refinement associated with the polymorphic transformation in the silicide [22], which might have caused grain-boundary strengthening sufficiently high to obscure the descending temperature region I. In Ni3 $\mathrm{Al}$, the bottom temperature is about $77 \mathrm{~K}\left(\mathrm{~T}_{\mathrm{b}}=0.05 \mathrm{~T}_{\mathrm{c}}\right)$, indicating that the temperature region $\mathrm{I}$, where Peierls stress is important, is relatively very narrow. The peaking of $\sigma_{y}$ at $T_{p}$ is attributed to the transition of active slip plane from (111) in the temperature region II to (010) in the region III.

Regardless of the details of the dislocation models proposed so far for the yield strength anomaly in $\mathrm{L}_{2} 2$ alloys, one common feature of these models is the tendency for $(1 / 2)[101]$ screw superpartials on the (111) primary slip plane to cross slip into the $(010)$ plane. The two driving forces for this process are the anisotropy of APB energies [23] and the interaction torque between the two superpartials [24] due to the elastic shear anisotropy, $\mathrm{A}=\mathrm{C}_{44} / \mathrm{C}^{\prime}$, where $\mathrm{C}^{\prime}=\left(\mathrm{C}_{11}-\mathrm{C}_{12}\right) / 2$. The calculated elastic constants [13,14] and $\mathrm{APB}$ energies [14,25] for stoichiometric Ni3 $\mathrm{Al}$ and $\mathrm{Ni} 3 \mathrm{Si}$ are listed in Table 2, where $\gamma_{0}$ and $\gamma_{1}$ are the APB energies on the (010) and (111) planes, respectively. According to the energy criterion derived for the [001] orientation [24], the number listed in the last column of Table 2 must exceed $\sqrt{3}$ in order for the cross-slip pinning process to take place [26]. This is satisfied for $\mathrm{Ni} 3 \mathrm{Al}$ but not for $\mathrm{Ni} 3 \mathrm{Si}$. Therefore, a single-phase stoichiometric $\mathrm{Ni} 3 \mathrm{Si}$, if it exists, is not likely to exhibit the yield strength anomaly by the cross-slip pinning mechanism.
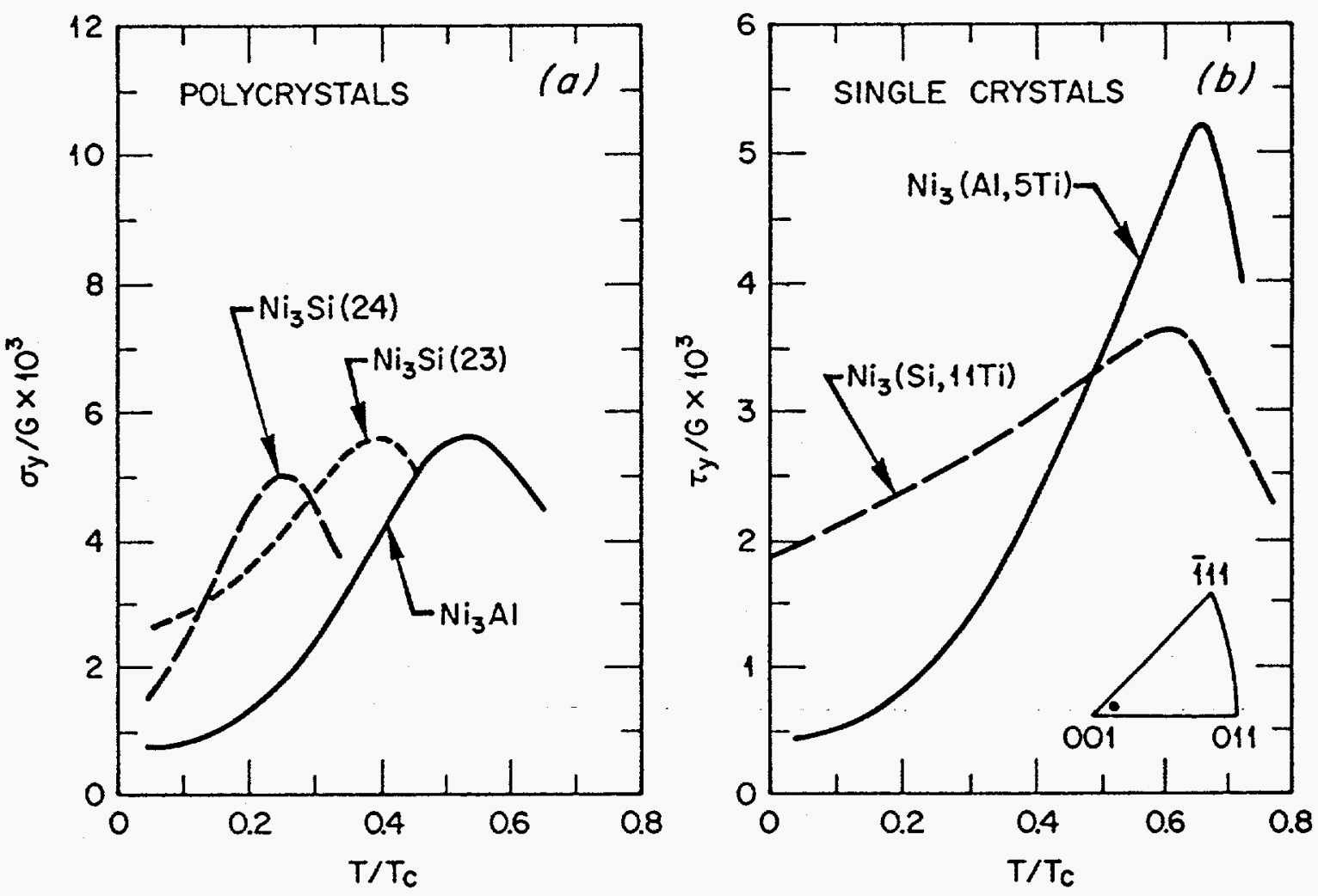

Figure 2. Temperature dependence of yield stress: (a) normal stress in Ni3 Al and $\mathrm{Ni} 3 \mathrm{Si}$ polycrystals and $(b)$ effects of $\mathrm{Ti}$ additions on CRSS in single crystals. 
Figure 2(b) shows the $\tau_{y} / G$ vs $T / T_{c}$ plot for Ni78(Si,Ti) [27] and $\mathrm{Ni} 3\left(\mathrm{Al}, \mathrm{STi}^{\dagger}{ }^{\dagger}[21]\right.$ single crystals. Yasuda, Takasugi, and Koiwa [28] measured the elastic anisotropy factor in $\mathrm{Ni78}(13 \mathrm{Si}, 9 \mathrm{Ti})$ to be $\mathrm{A}=2.8$, which gives $[3 \mathrm{~A} /(\mathrm{A}+2)]=1.75$, satisfying the energy criterion even for the isotropic case of APB energy (i.e., $\gamma_{0}=\gamma_{1}$ ). Our calculation of the (010) APB energy in $\mathrm{Ni} 3(\mathrm{Si}, \mathrm{Ti})$ gives $\gamma_{0}=360 \mathrm{~mJ} / \mathrm{m}^{2}$, which is considerably lower than that of $\mathrm{Ni} 3 \mathrm{Si}$ (Table 2). These two results support that the positive temperature dependence of $\tau_{y}$ in $\mathrm{Ni} 78(\mathrm{Si}, \mathrm{Ti})$ crystals is consistent with the cross-slip pinning mechanism. However, the inception of the yield strength anomaly at $0 \mathrm{~K}$, as shown by the straight dashed line in Figure $2(b)$, cannot be explained in terms of any thermally activated process of dislocations.

Table 2. Calculated Elastic Constants and APB Energies of Stoichiometric $\mathrm{Ni}_{3} \mathrm{Al}$ and $\mathrm{Ni}_{3} \mathrm{Si}$

\begin{tabular}{|c|c|c|c|c|c|c|}
\hline \multirow{2}{*}{ Alloy } & \multicolumn{3}{|c|}{$\left(10^{11} \mathrm{~N} / \mathrm{m}^{2}\right)$} & \multicolumn{2}{|c|}{$\left(\mathrm{mJ} / \mathrm{m}^{2}\right)$} & \multirow{2}{*}{$\left(\frac{3 \mathrm{~A}}{\mathrm{~A}+2}\right) \frac{\gamma_{1}}{\gamma_{0}}$} \\
\hline & $\mathrm{C}_{11}$ & $\mathrm{C}_{12}$ & $\mathrm{C}_{44}$ & $\gamma_{0}$ & $\gamma_{1}$ & \\
\hline $\mathrm{Ni}_{3} \mathrm{Al}$ & 2.35 & 1.45 & 1.32 & 140 & 220 & 2.33 \\
\hline $\mathrm{Ni}_{3} \mathrm{Si}$ & 3.75 & 2.00 & 1.67 & 707 & 620 & 1.28 \\
\hline
\end{tabular}

\section{B2 ALUMINIDES}

The compressive yield strength of $\mathrm{NiAl}$ measured in the so-called hard orientation $[29,30]$ is schematically shown in Figure 3 . As listed in Table 3, the active slip vector in NiAl at low temperatures is of the $<100>$ type. This is consistent with the high APB energies $\left[810\right.$ and $990 \mathrm{~mJ} / \mathrm{m}^{2}$ for (110) and (112) planes, respectively] and the relatively narrow dissociation widths (a few atomic spacings) obtained from $\mathrm{d}=\mathrm{Kb}^{2} / 2 \pi \gamma$ for the edge and screw characters [17]. In the hard [001] orientation, deformation by the $<100\rangle$ slip is prohibited, and the $\{112\}<111>$ slip occurs below $600 \mathrm{~K}\left(\mathrm{~T}=0.3 \mathrm{~T}_{\mathrm{c}}\right)$ and the $\{110\}<110\rangle$ slip above this temperature [30]. Deviation from stoichiometry to $\mathrm{Ni}-40 \mathrm{Al}$ gives rise to an appreciable increase in the yield stress below $1000 \mathrm{~K}\left(\mathrm{~T}<0.6 \mathrm{~T}_{\mathrm{C}}\right)$, which is consistent with the calculated equilibrium concentration of antisite ( $\mathrm{Ni}->\mathrm{Al})$ defects on the Ni-rich side [31]. The hypostoichiometric deviation gives an apparent extension of the athermal plateau to higher temperatures [29].

Mechanistic reasons for the appearance of athermal plateau in $\mathrm{NiAl}$ compressed along the hard orientation are not entirely clear. Recently, Takeuchi [32] proposed the Peierls mechanism of strongly interacting partial dislocations that describes the low-temperature and plateau regions as being controlled by the uncorrelated kink-pair formations on two partials and the high-temperature region by the correlated kink-pair formations. He claims

$\dagger$ Alloy compositions are given in at. \% throughout this paper. 


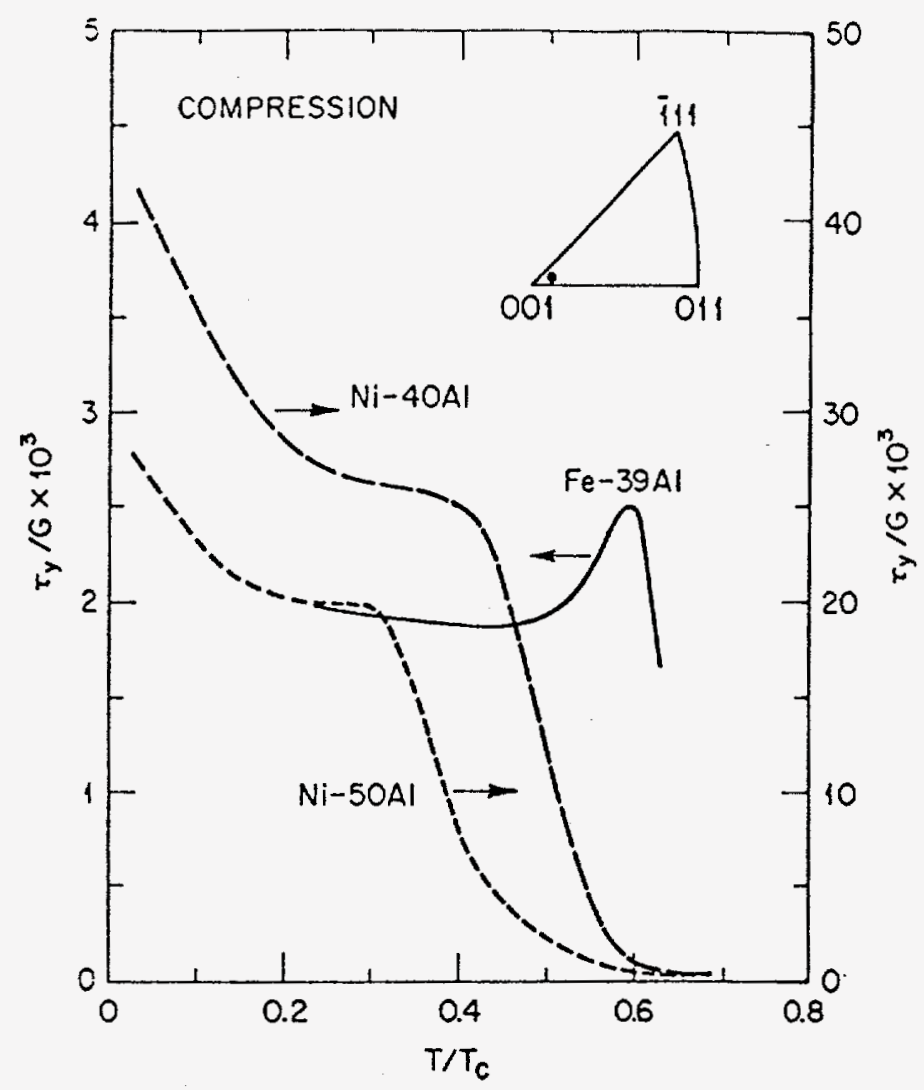

Figure 3. Temperature dependence of CRSS when compressive stress is applied along the [001] axis of $\mathrm{NiAl}$ and FeAl single crystals.

Table 3. Slip Vectors, APB Energies, Energy Factors, and Dissociation Widths for NiAl and FeAl at Low Temperatures

\begin{tabular}{ccccccc} 
Alloy & $\begin{array}{c}\text { Slip } \\
\text { vector }\end{array}$ & $\begin{array}{c}\gamma_{110} \\
\left(\mathrm{~mJ} / \mathrm{m}^{2}\right)\end{array}$ & $\frac{\left(10^{11} \mathrm{~N} / \mathrm{m}^{2}\right)}{\mathrm{K}_{\mathrm{e}}}$ & $\mathrm{K}_{\mathrm{s}}$ & & \multicolumn{2}{c}{$(\mathrm{nm})$} \\
\hline $\mathrm{NiAl}$ & {$[100]$} & 810 & 1.06 & 0.46 & 1.06 & 0.45 \\
$\mathrm{FeAl}$ & {$[111]$} & 300 & 1.66 & 1.00 & 5.31 & 3.21 \\
\hline
\end{tabular}

that the plateau exhibited in NiAl by the $\{11 \overline{2}\}<111>$ slip system can be interpreted by this mechanism. Another possibility is that the plateau appears simply from superposition of a thermally activated strengthening due to the $\{112\}<1.11\rangle$ - superdislocations and the strong Peierls stress $\left(\tau_{0}\right)$ for the dislocations. In other words, the magnitude of $\tau_{0}$ is large, and the temperature region $I$ is wide enough such that $\tau_{b}$ reaches the same level as $\tau_{p}$ in Figure 1.

Deformation behavior of $\mathrm{FeAl}$ has been recently reviewed by Baker [33]. The solid curve in Figure 3 shows the yield strength anomaly in Fe-39Al single crystals that were fully annealed to remove frozen-in vacancies [34]. The slip mode below $T_{p}$ was found to be mainly (101)[111], and at $T_{p}$ and above, non-[111] slip operates predominantly. Thus, the yield strength 
anomaly in $\mathrm{FeAl}$ is similar to that in $\beta-\mathrm{CuZn} \mathrm{[13]} \mathrm{as} \mathrm{far} \mathrm{as} \mathrm{the} \mathrm{slip} \mathrm{transition} \mathrm{at}$ $\mathrm{T}_{\mathrm{p}}$ is concerned.

As for possible mechanisms for glide resistance, some kind of temperature-dependent barriers against the motion of $\langle 111\rangle$ dislocations are needed to explain the yield strength anomaly. The cross-slip pinning mechanism is not applicable because of the lack of driving force, i.e., the APB energy is much higher for the (211) plane than for the (101) plane [17,23], and the torque term of elastic interaction force between the superpartial pair is zero on these planes [35]. Since thermal vacancy concentration in $\mathrm{B} 2 \mathrm{FeAl}$ increases dramatically above $973 \mathrm{~K}\left(0.65 \mathrm{~T}_{\mathrm{c}}\right)$, e.g., $1.0 \times 10^{-3} \sim 10^{-2}$ around $1173 \mathrm{~K}\left(0.8 \mathrm{~T}_{\mathrm{c}}\right)$ [36], it could be presumed that the long-range ordering parameter, $S$, is substantially lower than one even at $0.6 \mathrm{~T}_{\mathrm{c}}$. In addition, the (101) APB energy of $\mathrm{Fe}-39 \mathrm{Al}$ at elevated temperature is expected to be much lower than $300 \mathrm{~mJ} / \mathrm{m}^{2}$ calculated for $\mathrm{FeAl}$ at $0 \mathrm{~K}[17]$. Thus, the APB dragging mechanism [10] seems rather attractive for this case. This cannot be the only mechanism to explain the yield strength anomaly, however, because $\tau_{\mathrm{y}}$ in the temperature region III descends steeply pointing toward $\mathrm{T}<0.7 \mathrm{~T}_{\mathrm{c}}$, not toward $\mathrm{T}_{\mathrm{c}}$. We are then left with the climb/glide dissociation mechanism $[12,13]$, which is based on the self-feeding short-circuit diffusion along the APB interface between the superpartial pair. In FeAl, the climb component of partial dislocation motion will be influenced strongly by the high concentration of thermal vacancies available in the matrix.

Transmission electron microscopy (TEM) analysis of deformed $\mathrm{Fe}-39 \mathrm{Al}$ crystals revealed that the dislocation microstructure consisted typically of two types, i.e., long and straight screw dislocations and long but wavy edge dislocations [34]. Also found to occur prevalently in the TEM micrographs was the decomposition of a [111] dislocation into a [010] and a [101] dislocation, which was suggested for a relatively high APB energy case [37]. As was mentioned earlier for $\mathrm{FeAl} \mathrm{[34]} \mathrm{and} \mathrm{NiAl}[37,38]$, the line tension instability due to elastic anisotropy plays an important role in the glide decomposition process. Since the Zener's factor becomes very large at transition-metal rich compositions (e.g., $A=4.2$ for $\mathrm{Fe}-40 \mathrm{Al}$ and $\mathrm{A}>7.0$ for $\mathrm{Ni}-40 \mathrm{Al}$ ), this factor may play a significant role in formulating a dislocation mechanism responsible for the yield strength anomaly observed in $\mathrm{Fe}-39 \mathrm{Al}$ crystals.

\section{TITANIUM ALUMINIDES}

Deformation behavior characteristics of $\gamma$-TiAl alloys have been reviewed recently by Yamaguchi and Inui [39]. In two-phase $(\gamma-\alpha 2)$ TiAlTi3Al alloys, the strong dependence of yield strength on lamellar orientation is believed to originate from the markedly different yield strengths of TiAl and $\mathrm{Ti} 3 \mathrm{Al}$, particularly along the normal $(\mathrm{N})$ orientation of the $\alpha 2$ phase, i.e., the [0001] orientation. Deformation twinning plays a very important role in the plastic anisotropy of these two-phase lamellar crystals, the so-called polysynthetically twinned (PST) structure [40]. Those readers who are interested in further information on the role twinning plays in mechanical behavior of TiAl are referred to the papers [42-48] in a recent monograph [41].

The short-dashed curve for $\mathrm{TiAl}$, shown in Figure 4 represents schematically the two data reported by Kawabata et al. $[49,50]$, one from Alrich (composition unspecified) alloys at 293 to $1273 \mathrm{~K}\left(0.17\right.$ to $\left.0.73 \mathrm{~T}_{\mathrm{c}}\right)$ and the other from $\mathrm{Ti}-56 \mathrm{Al}$ single crystals at 4.2 to $293 \mathrm{~K}\left(\mathrm{~T}<0.17 \mathrm{~T}_{\mathrm{c}}\right)$. More recent data on $\mathrm{Ti}-55.9 \mathrm{Al}$ single crystals [51] are also shown in Figure 4 by the solid curve. Since the $\{111\}<1 \overline{0}]$ slip system by ordinary dislocations cannot 


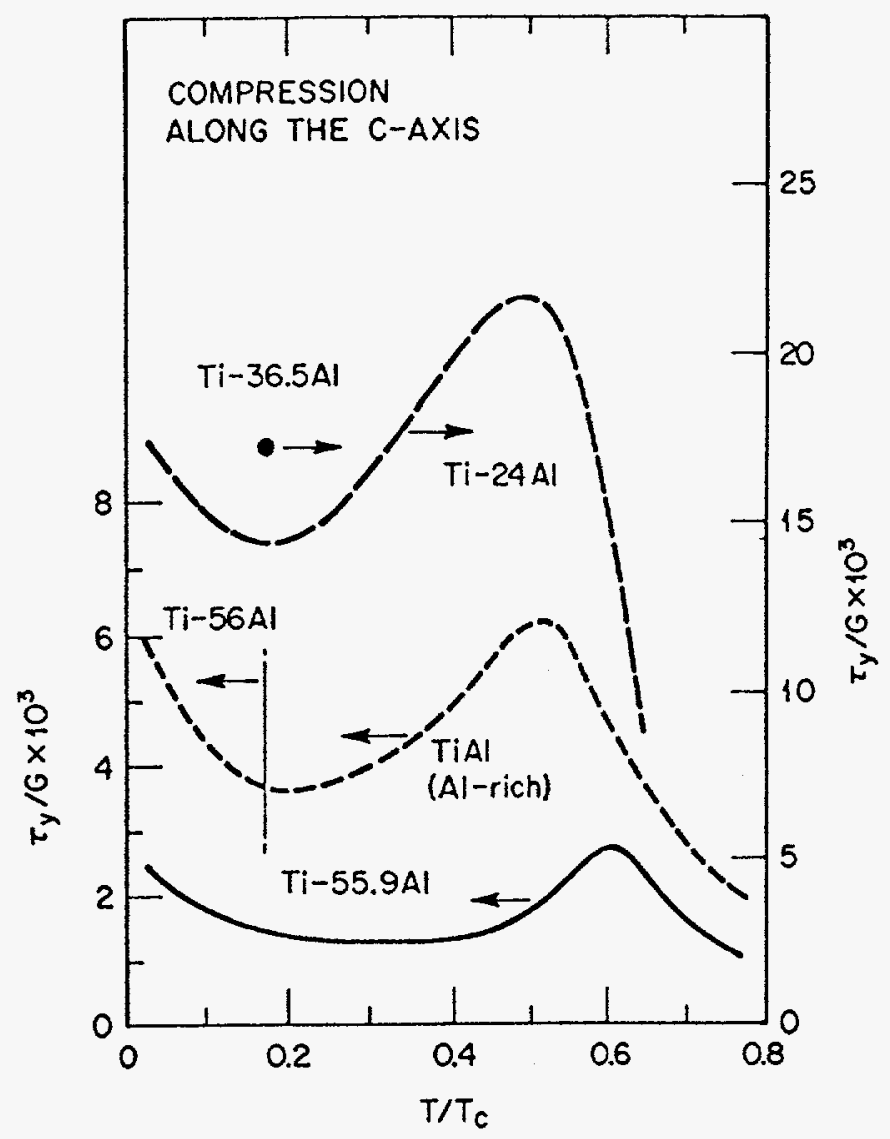

Figure 4. Temperature dependence of CRSS when compressive stress is applied along the c-axis of $\mathrm{TiAl}$ and $\mathrm{Tiz} \mathrm{Al}$ single crystals.

be activated in this case, the $\{111\}<101]$ slip system by superdislocations and the $\{111\}<112]$ twin system by $(1 / 6)<112\}$ true (ordered)-twinning partial dislocations must contribute to the observed yield behavior. Inui and Yamaguchi [51] found that the superdislocations operated below $T_{p}$ and the deformation twinning above $\mathrm{T}_{\mathrm{p}}$. Mechanistic interpretation of the experimental data is under preparation.

As compared to the yield strength of $\gamma$-TiAl, $\alpha_{2}-\mathrm{Ti}_{3} \mathrm{Al}$ shows exceptionally high yield strength [52] as shown in Figure 4 by the longdashed curve. For instance, the ratios of $\tau_{b}$ and $\tau_{p}$ between Ti-24Al and Ti$55.9 \mathrm{Al}$ are approximately 11 and 8 , respectively. At room temperature, $\tau_{\mathrm{y}}$ of $\mathrm{Ti}-36.5 \mathrm{Al}$ (an off-stoichiometry similar to the actual composition of $\alpha 2$ plates in PST crystals) is even higher $(911 \mathrm{MPa})$ [53] than that of $\mathrm{Ti}-24 \mathrm{Al}(\sim 470$ $\mathrm{MPa})[52]$.

When compressive stress is applied along the c axis of Ti3 $\mathrm{Al}$, both prism and basal slip systems with the $<a>$ Burgers vectors are not operative, and the $\{1121\}(1 / 3)\langle 1126\rangle$ pyramidal slip system becomes the active deformation mode. Deformation twinning does not occur in the D019 structure because of difficulty associated with the so-called interchange shuffling [54]. Since the $2 \mathbf{c}+\mathbf{a}$ superdislocations are observed mostly in edge or near-edge orientation $[55,56]$, the APB dragging mechanism, in analogy with the $\{11 \overline{2}\}<111>$ slip in the B2 structure, is an attractive mechanism for explaining the yield strength anomaly in TizAl. Our recent calculations of the elastic constants and the (1121) APB energy of $293 \mathrm{~mJ} / \mathrm{m}^{2}$ give the equilibrium width between two $\mathbf{c}+\mathbf{a} / 2$ superpartials to be about $16 \mathrm{~nm}$ for the edge orientation [19]. This relatively large width results from the large Burgers vector of the superpartials. Much more work is needed to elucidate 
the physical source of high yield stress and the yield strength anomaly in Ti $3 \mathrm{Al}$, including a study of the core structure and the mobility of an individual $\mathbf{c}+\mathbf{a} / 2$ superpartial dislocation.

\section{DISCUSSION AND SUMMARY}

Since $\mathrm{Ni} 3 \mathrm{Si}$ has just one more p-electron than $\mathrm{Ni3} \mathrm{Al}$, slight differences in the atomic weights and the lattice parameters give rise to an almost identical mass density, $\rho=7.9 \mathrm{~g} / \mathrm{cm}^{2}$ (Table 1). The polarization of the extra p-electron occurs directly along the $\mathrm{Ni}-\mathrm{Si}$ nearest-neighbor directions on the cube planes [57]. It is the directional/covalent $\mathrm{Ni}$-Si bonding, due to this polarization, that results in high elastic moduli and shear fault energies. In direct comparison to $\mathrm{Ni} 3 \mathrm{Al}$, the anisotropy of APB energy and the elastic shear anisotropy are reduced to such levels that the cross-slip process from the (111) plane onto the (010) plane is not feasible for Ni3Si.

The bonding mechanism in late transition-metal aluminides of the B2 structure can be best described by the combination of charge transfer and strong p-d hybridization effects [17]. The high APB energies of NiAl (and hence the strong ordering), as compared to $\mathrm{FeAl}$, can be attributed mainly to the size difference between $\mathrm{Ni}$ and $\mathrm{Al}$ atoms. This size effect, together with the electronic d-band structure of $\mathrm{NiAl}$, makes its bulk and defect properties so unique that small alloying additions (e.g., $\mathrm{Cr}$ ) to convert the active slip vector from the $\langle 100\rangle$ type to the $\langle 111\rangle$ type are essentially ineffective [30]. On the other hand, FeAl possesses many attributes of metallic characters in its bulk and defect properties, including the relatively low vacancy formation energy and high divacancy binding energy that lead to the tendency for vacancy clustering. Consequently, deformation behavior of $\mathrm{FeAl}$ is rather complicated as a result of the evolving dislocation microstructure.

In contrast to the above two cases, bulk properties and shear fault energies of TiAl and $\mathrm{Ti} 3 \mathrm{Al}$ are not too different except the marked difference between the twin boundary energy, $60 \mathrm{~mJ} / \mathrm{m}^{2}$, and the (111) APB energy, $510 \mathrm{~mJ} / \mathrm{m}^{2}$, of TiAl [18]. The propensity of deformation twinning reported in $\gamma$-TiAl alloys is consistent with the low value of twin boundary energy. The physical reasons for enhanced twinning in $\gamma$-TiAl at high temperatures and/or under low strain rate remain an open question. On one hand, direct comparison of deformation behavior between TiAl and Ti3 Al is not justified because two different crystal structures are involved. On the other hand, because of the crystallographic habit relationship between $\gamma$ and $\alpha 2$ phases in the PST crystals [39], further understanding of the $\{1121\}(1 / 3)<1126\rangle$ slip mechanism in TizAl is needed in order to properly assess the plastic anisotropy of two-phase $\gamma$-TiAl alloys.

Finally, in summary, two points are noteworthy. First, even though the common bases for comparative assessments of the three pairs of intermetallic alloys were selected (i.e., the crystal structures for the first two and the binary phases for the last), each alloy exhibits unique bulk and defect properties and hence very different deformation behavior. Second, because of this uniqueness of each alloy, it is imperative to develop relevant interatomic potentials that are consistent with the first-principles totalenergy calculations before they are applied to study the core structure and the mobility of superdislocations. 
The author gratefully acknowledges $H$. Inui and $M$. Yamaguchi for releasing the data on Ti-55.9Al single crystals before publication and E. P. George and Y. Mishima for helpful discussions. This research was sponsored by the Division of Materials Sciences, Office of Basic Energy Sciences, U.S. Department of Energy under contract DE-AC05-84OR21400 with Martin Marietta Energy Systems, Inc., and in part by the Alexander von Humboldt Foundation, Germany.

\section{REFERENCES}

1. High-Temperature Ordered Intermetallic Alloys V, ed. I. Baker, R. Darolia, J. D. Whittenberger, and M. H. Yoo, MRS Symp. Proc. 288, Pittsburgh, Pa, 1993.

2. High-Temperature Aluminides and Intermetallics, ed. D. P. Pope, C. T. Liu, and S. H. Whang, ASM Symp. Proc., Materials Park, Ohio, 1994.

3. International Symposium of Structural Intermetallics, ed. R. Darolia, J. J. Lewandowski, C. T. Liu, P. L. Martin, D. B. Miracle, and M. V. Nathal, TMS Symp. Proc., Warrendale, Pa, 1993.

4. Yamaguchi, M. and Umakoshi, Y.: Prog. Mater. Sci. 34, 1 (1990).

5. Yoo, M. H., Sass, S. L., Fu, C. L., Mills, M. J., Dimiduk, D. M., and George, E. P.: Acta Metall. Mater. 41, 987 (1993).

6. Yoo, M. H., Horton, J. A. and Liu, C. T.: Acta Metall. 36, 2935 (1988).

7. Yoshimi, K. and Hanada, S.: p. 475 in ref. 3.

8. Minonishi, Y. and Yoo, M. H.: Phil. Mag. Lett. 61, 203 (1990).

9. Kocks, U. F., Argon, A. S., and Ashby, M. F.: Prog. Mater. Sci. 19, Thermodynamics and Kinetics of Slip, Pergamon Press, 1975.

10. Brown, N.: Phil. Mag. 4, 693 (1959).

11. Takeuchi, S. and Kuramoto, E.: Acta Metall. 21, 415 (1973).

12. Veyssiere, P.: Phil. Mag. A $\underline{50,} 189$ (1984).

13. Zhu, Y. M. and Saka, H.: Philos. Mag. A 59, 661 (1989).

14. Binary Phase Diagrams, Vols. 1 and 2, ed. T. B. Massalski, ASM, Metals Park, Ohio, 1986.

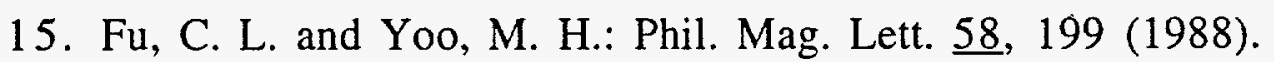

16. Fu, C. L., Ye, Y. Y., and Yoo, M. H.: Phil. Mag. Lett. 67, 179 (1993).

17. Fu, C. L. and Yoo, M. H.: Acta Metall. Mater. 40, 703 (1992).

18. Fu, C. L. and Yoo, M. H.: Phil. Mag. Lett. 62, 159 (1990).

19. Zou, J., Fu, C. L., and Yoo, M. H.: Acta Metall. Mater. (submitted). 
20. Pope, D. P. and Ezz, S. S.: Int. Metall. Rev. 29, 136 (1984).

21. Suzuki, T., Mishima, Y., and Miura, S.: ISIJ Int. 29, 1 (1989).

22. Suzuki, T., Oya, Y., and Ochiai, S.: Metall. Trans. 15A, 173 (1984).

23. Flinn, P. A.: Trans. AIME 218, 145 (1960).

24. Yoo, M. H.: Scr. Metall. $\underline{20}, 915$ (1986).

25. Fu, C. L. and Yoo, M. H.: High-Temperature Ordered Intermetallic Alloys III, ed. C. T. Liu, A. I. Taub, N. S. Stoloff, and C. C. Koch, MRS Symp. Proc. 133, Pittsburgh, Pa, 1989, p. 81.

26. Paidar, V., Pope, D. P., and Vitek, V.: Acta Metall. 32, 435 (1984).

27. Takasugi, Y. and Yoshida, M.: Philos. Mag. A $\underline{65}$, 613 (1992).

28. Yasuda, H., Takasugi, Y., and Koiwa, M.: Acta Metall. Mater. 40, 381 (1992).

29. Noebe, R. D., Bowman, R. R., and Nathal, M. V.: Int. Mater. Rev. $\underline{8}, 193$ (1993).

30. Miracle, D. B.: Acta Metall. Mater. 41, 649 (1993).

31. Fu, C. L., Ye, Y. Y., Yoo, M. H., and Ho, K. M.: Phys. Rev. B 4ㄹ, 6712 (1993).

32. Takeuchi, S.: Technical Report of ISSP, University of Tokyo, June, 1994 (to be submitted to Philos. Mag. A).

33. Baker, I.: Processing, Properties, Applications of Iron Aluminides, ed. J. H. Schneibel and M. A. Crimp, TMS Symp. Proc., Warrendale, Pa, 1994, p. 101 .

34. Yoshimi, K., Matsumoto, N., Hanada, S., and Yoo, M. H.: Ibid. p. 205.

35. Yoo, M. H.: High-Temperature Ordered Intermetallic Alloys II, ed. N. S. Stoloff, C. C. Kock, C. T. Liu, and O. Izumi, MRS Symp.. Proc. $\underline{81}$, Pittsburgh, Pa, 1987, p. 207.

36. Ho, K. and Dodd, R. A.: Scr. Metall. 121055 (1967).

37. Yoo, M. H., Takasugi, T., Hanada, S., and Izumi, O.: Mater. Trans. JIM $\underline{31}$, 435 (1990).

38. Yoo, M. H. and Fu, C. L.: ISIJ Int. 31, 1049 (1991).

39. Yamaguchi, M. and Inui, H.: p. 127 in ref. 3.

40. Fujiwara, T., Nakamura, A., Hosomi, M., Nishitani, S., Shirai, Y., and Yamaguchi, M.: Phil. Mag. A 61, 591 (1990).

41. Twinning in Advanced Materials, ed. M. H. Yoo and M. Wuttig, TMS Symp. Proc., Warrendale, Pa, 1994.

42. Yoo, M. H., Fu, C. L., and Lee, J. K.: p. 97 in ref. 41.

43. Yamaguchi, M., Inui, H., and Shirai, Y.: p. 177 in ref. 41. 
44. Appel, F. and Wagner, R.: p. 317 in ref. 41.

45. Gray, G. T.: p. 337 in ref. 41 .

46. Couret, A., Farenc, S., Caillard, D., and Coujou, A.: p. 361 in ref. 41.

47. Jin, Z. and Bieler, T. R.: p. 375 in ref. 41.

48. Seshagiri, S., Viswanathan, G. B., and Vasudevan, V. K.: p. 383 in ref. 41 .

49. Kawabata, T., Kanai, T., and Izumi, O.: Acta Metall. 33, 1355 (1985).

50. Kawabata, T., Abumya, T., Kanai, T., and Izumi, O.: Acta Metall. Mater. $\underline{38}$, 1381 (1990).

51. Inui, H. and Yamaguchi, M.: (unpublished work).

52. Minonishi, Y.: Intermetallic Compounds for High-Temperature Structural Applications, ed. M. Yamaguchi and H. Fukutomi, Proc. 3rd Japan Int. SAMPE, 1993, p. 1501.

53. Inui, H., Toda, Y., and Yamaguchi, M.: Philos. Mag. A 67, 1315 (1993).

54. Yoo, M. H., Fu, C. L., and Lee, J. K.: J. Phys. III 1, 1065 (1991).

55. Minonishi, Y.: Phil. Mag. A 63, 1085 (1991).

56. Court, S. A., Lofvander, J.P.A., Loretto, M. H., and Fraser, H. L.: Philos. Mag. A, 1989, 오 379 (1989).

57. Fu, C. L., Ye, Y. Y., and Yoo, M. H.: p. 21 in ref. 1. 